\title{
Course of Depressive Symptoms Following a Workplace Injury: A 12-Month Follow-Up Update
}

\author{
Nancy Carnide ${ }^{1,2} \cdot$ Renée-Louise Franche $^{1,3,4,5} \cdot$ Sheilah Hogg-Johnson ${ }^{1,2}$. \\ Pierre Côté2,6 $^{2}$ F. Curtis Breslin ${ }^{1,2,7} \cdot$ Colette N. Severin ${ }^{1}$ • Ute Bültmann ${ }^{1,8}$. \\ Niklas Krause ${ }^{9}$
}

(C) Springer Science+Business Media New York 2015

\begin{abstract}
Introduction To estimate the prevalence, incidence and course of depressive symptoms, their relationship with return-to-work, and prevalence of depression diagnosis/treatment 12 months following a lost-time workplace musculoskeletal injury. Methods In a prospective cohort study, 332 workers' compensation claimants with a back or upper extremity musculoskeletal disorder completed interviews at 1,6 and 12 months post-injury. Participants self-reported they had not received a depres-
\end{abstract}

Nancy Carnide

ncarnide@iwh.on.ca

1 Institute for Work \& Health, 481 University Avenue, Suite 800, Toronto, ON M5G 2E9, Canada

2 Dalla Lana School of Public Health, University of Toronto, Toronto, ON, Canada

3 WorkSafe BC, Vancouver, BC, Canada

4 Faculty of Health Sciences, Simon Fraser University, Vancouver, BC, Canada

5 School of Population and Public Health, University of British Columbia, Vancouver, BC, Canada

6 Faculty of Health Sciences, University of Ontario Institute of Technology, Oshawa, ON, Canada

7 General Education Department, Seneca College of Applied Arts and Technology, Toronto, ON, Canada

8 Department of Health Sciences, Community and Occupational Medicine, University Medical Center Groningen, University of Groningen, Groningen, The Netherlands

9 Department of Environmental Health Sciences and Department of Epidemiology, Fielding School of Public Health, University of California Los Angeles, Los Angeles, CA, USA sion diagnosis 1 year pre-injury. Cutoff of 16 on the CESD defined a high level of depressive symptoms. Self-reported data on depression diagnosis and treatment and work status since injury were collected. Results Cumulative incidence of high depressive symptom levels over 12 months was $50.3 \%$ (95\% CI $44.9-55.7 \%)$. At 12 months, $24.7 \%$ (95\% CI 20.1-29.3\%) of workers exhibited high levels. Over 12 months, $49.7 \%$ (95\% CI 44.3-55.1\%) had low levels at all 3 interviews, $14.5 \%$ (95\% CI 10.7-18.2\%) had persistently high levels, and $25.6 \%$ (95\% CI 20.9-30.3\%) demonstrated improvements. Among workers with low baseline levels, incidence of high levels at 12 months was $6.0 \%(95 \% \mathrm{CI}$ 2.7-9.3\%). For workers with high baseline levels, $36.1 \%$ (95\% CI 27.9-44.3\%) exhibited persistent high symptoms at 6 and 12 months, while $38.4 \%$ (95\% CI 30.1-46.6\%) experienced low levels at 6 and 12 months. Problematic RTW outcomes were common among workers with a poor depressive symptom course. Among workers with persistent high symptoms, $18.8 \%$ (95\% CI 7.7-29.8\%) self-reported receiving a depression diagnosis by 12 months and $29.2 \%$ (95\% CI $16.3-42.0 \%$ ) were receiving treatment at 12 months. Conclusions Depressive symptoms are common in the first year following a lost-time musculoskeletal injury and a poor depressive symptom course is associated with problematic RTW outcomes 12 months post-injury. While symptoms appear to improve over time, the first 6 months appear to be important in establishing future symptom levels and may represent a window of opportunity for early screening.

Keywords Depression - Occupational injuries · Workers' compensation 


\section{Introduction}

In 2013, 241,933 lost-time work-related injuries were documented in Canada [1]. The personal, physical, and financial toll of workplace injuries on workers is enormous. In particular, depressive symptoms have been found to be a common occurrence following a workplace musculoskeletal injury [2-5] and their presence has been shown to be associated with poorer work outcomes [4, 6-9]. However, there is scarce research examining injured workers' mental health trajectories and the course of depressive symptoms, particularly over an extended time post-injury. Furthermore, previous data linking depressive symptoms and work outcomes have been limited to onetime measures of mental health. Little is known about the relationship between temporal patterns in depressive symptoms and working status.

We partially addressed this research gap in a previous report on the 6-month follow-up of workers with musculoskeletal (MSK) injuries [3]. Prevalence of high depressive symptom levels at 1 month was $42.9 \%$ and at 6 months was $26.5 \%$. Our most significant findings pertained to symptom course: $52.8 \%$ of workers with high depressive symptom levels 1 month post-injury experienced symptom resolution by 6 months, suggesting some injured workers may experience reactive and transient depressive symptoms following injury. For the other $47.2 \%$, high symptom levels persisted and few reported receiving a depression diagnosis or treatment. Persistence of high depressive symptom levels and incident high levels at 6 months were also more likely to occur in those with problematic return-to-work (RTW) trajectories compared with those with a sustained RTW.

This short follow-up, however, raises questions regarding the long-term stability of depressive symptom levels postinjury and the importance of post-injury symptom course in relation to work outcomes. The objectives of the current study are to estimate the prevalence, incidence, and course of depressive symptoms and their relationship with return-towork (RTW) outcomes, as well as the prevalence of depression diagnosis and treatment, over 12 months post-injury.

\section{Methods}

\section{Population and Recruitment}

We conducted a prospective cohort study of Ontario workers filing a new Workplace Safety \& Insurance Board of Ontario (WSIB) lost-time claim for a work-related MSK back or upper extremity soft-tissue disorder from 2005 to 2007 (methods described in detail elsewhere [3, 10-12]). Eligibility criteria included: work absence of at least 5 days within 14 days following injury, claim filing within 7 days of injury, and 15 years of age or older. Claimants who could not understand or speak English, who had severe injuries, or were receiving institutional care were not eligible to participate.

Workers were first screened for eligibility and contacted by WSIB staff to request their permission to be contacted by a university-based survey unit. An information sheet and consent form were mailed to workers who agreed. Workers were assured that study participation would not affect their interactions with the WSIB, their employer, or health care provider. A university-based interviewer then contacted potential participants to describe the study, request verbal consent to participate, and to perform a final eligibility screen. The study was approved by the University of Toronto Ethics Review Board.

A total of 632 eligible claimants completed the baseline interview at 1 month (61\% participation) and 345 workers completed all 3 interviews (55\% retention). These participation and retention rates are similar to those found in comparable studies $[13,14]$.

\section{Data Collection}

Telephone interviews were conducted at 1 (baseline), 6, and 12 months post-injury to gather information on sociodemographics, the workplace, the RTW and injury experience, and worker's health. WSIB administrative data consisting of sociodemographic, workplace, and claim information were also gathered and linked to interview data when written consent for linkage was provided $(n=481$ baseline participants).

\section{Main Study Variables}

\section{Depressive Symptoms, Diagnosis, and Treatment}

The Center for Epidemiologic Studies Depression Scale (CES-D) [15] was used to measure depressive symptoms at 1 (baseline), 6, and 12 months post-injury. Workers reported the frequency of experiencing 20 depressive symptoms in the past week on a 4-point scale ranging from " $<1$ day" to "5-7 days". Scores range from 0 to 60 , with higher scores indicating more symptoms. We defined a high level of depressive symptoms as a CES-D score $\geq 16$ and a low level as a CES-D score $<16$. This cutoff has been shown to be an indicator of significant depressive symptomatology [15]. The sensitivity and specificity of this cutoff for detecting depressive disorders has been demonstrated to range from 64 to $100 \%$ and 39 to $94 \%$, respectively, in community, primary care, and pain populations [16-22]. The positive predictive value (PPV) and negative predictive value (NPV) of this cutoff have ranged 
from 14 to $63 \%$ [16-21] and 78 to $99 \%$ [17, 19-21], respectively. In the original sample [15], the scale demonstrated high internal consistency, ranging from 0.85 in the general population sample to 0.90 in the psychiatric patient sample. The internal consistency of the scale in our baseline sample was 0.92 .

At 6 and 12 months, workers were also asked to selfreport whether they had received a depression diagnosis since their injury and whether they were currently using anti-depressants and/or consulting with a healthcare provider about their mental health (yes/no).

\section{Work Status}

Current work status (working/not working) was measured by 1 self-reported yes/no question at each of the 3 interviews: "Are you currently working at any job right now?".

\section{RTW Trajectory}

RTW trajectory was measured at each of the 3 follow-up interviews using self-reported information on current work status (described above) and number of attempts to return to work since the injury. Workers were categorized into 1 of 3 categories:

- RTW-S: Sustained first RTW-workers who returned to work and remained at work after their first RTW attempt.

- RTW-R: RTW with recurrence(s) of work absenceworkers who returned to work, but did not remain at work after their first RTW attempt and may or may not have been working at the time of interview.

- No RTW: Workers who have never made a return to work attempt at time of interview.

\section{Other Variables}

At baseline, workers were asked to provide information on sociodemographic characteristics, including age, sex, and education level, as well as workplace factors, such as work hours. Work absence duration was self-reported at baseline as the total number of full work days missed due to the workplace injury.

Workers were also asked to rate the intensity of their current level of pain using 1 item from the Von Korff Pain Scale [23]. Intensity was measured on an 11-point scale ranging from $0=$ no pain to $10=$ pain as bad as could be . Functional disability at baseline was measured using the Roland Morris Disability Questionnaire [24] for workers with back pain and the QuickDASH [25] for workers with upper extremity pain. Total scores were converted to standardized $\mathrm{z}$ scores, with a higher standardized score indicating greater disability. For workers with both back and upper extremity pain, the highest $\mathrm{z}$ score was used as the index of functional status and also determined primary pain site.

\section{Analysis}

Analyses were restricted to workers who completed all interviews and provided complete CES-D data $(\mathrm{n}=344)$. We excluded those who self-reported a depression diagnosis in the year before injury $(\mathrm{n}=12)$ in an attempt to establish a sample that did not have depression at the time of injury. As a result, our final sample consisted of 332 workers.

Course of depressive symptoms was categorized into 8 symptom trajectory groups, reflecting the 8 possible trajectories based on the three time points (1, 6 and 12 months):

- Stable Low: low/low/low

- Incidence at 12 months: low/low/high

- Resolution of 6-month incidence: low/high/low

- Persistence of 6-month incidence: low/high/high

- Maintenance of 6-month resolution: high/low/low

- Recurrence at 12 months: high/low/high

- Resolution at 12 months: high/high/low

- Persistence: high/high/high

A subset of the categories above were also collapsed into 'improvement in symptoms' (low/high/low, high/low/ low, high/high/low) and 'deterioration in symptoms' (low/ low/high, low/high/high, high/low/high). RTW trajectory groups were collapsed into 2 groups: RTW-S (sustained first RTW), and RTW-R/No RTW (problematic RTW). Previous analyses of the baseline sample suggested that the RTW-R and No RTW groups experienced similar health outcomes [10].

The following measures were calculated:

1. Cumulative incidence and prevalence of high levels of depressive symptoms at 12 months post-injury, along with the mean and median CES-D score and standard deviation (SD), stratified by sex, baseline depressive symptom level, RTW trajectory, and working status;

2. Frequency of each of the 8 symptom trajectory groups in the overall sample and as a function of baseline symptoms;

3. Frequency of working status and RTW trajectory stratified by symptom course groups;

4. Probability of exhibiting a high or low symptom level at 6 and 12 months conditional on the symptom level at the time point immediately preceding;

5. Crude 12-month period prevalence of a depression diagnosis and the crude point prevalence of mental health treatment (antidepressant use and/or speaking with a health professional) at 6 and 12 months for the 
overall sample, as well as stratified by symptom course groups.

The $95 \%$ confidence intervals (CI) were calculated around all estimates. All analyses were also stratified by sex. Sensitivity analyses examined the impact of using a CES-D cutoff of 19 (previously validated for chronic pain patients [21]).

\section{Results}

The mean age of participants at baseline was 44.3 years (SD 10.3) and $54.5 \%$ of workers in the sample were men (Table 1). More than half of the workers in this study had completed at least some post-secondary education $(59.3 \%)$ and $64.8 \%$ had a back injury. By 1 month, two-thirds of workers had made a return-to-work attempt, either sustained $(49.1 \%)$ or with at least 1 recurrence of absence $(14.6 \%)$, and mean self-reported work absence duration was 14.1 days (SD 6.5, median 14.0 days). Mean CES-D score at baseline was 14.6 (SD 11.6, median 11.0).

\section{Cumulative Incidence and Prevalence of High Levels of Depressive Symptoms at 12 Months Post- injury by Sex, Baseline Depressive Symptom Level, RTW Trajectory, and Work Status (Table 2)}

The cumulative incidence of high depressive symptom levels over 12 months was $50.3 \%$ (95\% CI 44.9-55.7\%; Table 2). The cumulative incidence among those with a more problematic RTW trajectory $(60.7 \%, 95 \%$ CI 53.9-67.6\%) was greater than in those with a RTW-S trajectory (35.3\%, $95 \%$ CI 27.3-43.3\%). Likewise, cumulative incidence of high levels were significantly higher in workers not working at 12 months $(72.0 \%, 95 \%$ CI $61.8-82.2 \%$ ) compared to those currently working (44.0\%, $95 \%$ CI 37.9-50.0\%). Women had a non-significantly higher cumulative incidence $(57.6 \%, 95 \% \mathrm{CI}$ 49.7-65.5\%) compared to men (44.2\%, $95 \%$ CI $37.0-51.4 \%)$.

The 12-month post-injury prevalence of high depressive symptom levels was $24.7 \%$ (95\% CI 20.1-29.3\%) and was higher among women $(29.1 \%, 95 \%$ CI 21.9-36.4 \%) compared to men $(21.0 \%$, $95 \%$ CI $15.1-26.9 \%$; Table 2). Similar to the findings with cumulative incidence, prevalence was highest among those not currently working at 12 months and among those with a RTW-R/No RTW trajectory. The 12-month prevalence among those with low levels at baseline was $9.1 \%$, while approximately half of workers with high levels at baseline also had high levels at 12 months $(48.1 \%, 95 \%$ CI 39.6-56.6 \%).
Table 1 Characteristics of the total sample at baseline $(\mathrm{n}=332)$

\begin{tabular}{|c|c|}
\hline Variable* & $\begin{array}{l}\text { Total sample } \\
(\mathrm{n}=332)\end{array}$ \\
\hline \multicolumn{2}{|l|}{ Gender, no. (\%) } \\
\hline Women & $151(45.5)$ \\
\hline Men & $181(54.5)$ \\
\hline Age, mean (SD), median & $44.3(10.4), 45.0$ \\
\hline \multicolumn{2}{|l|}{ Sex $\times$ Age, no. $(\%)$} \\
\hline \multicolumn{2}{|l|}{ Women } \\
\hline 15-29 years & $21(13.9)$ \\
\hline 30-39 years & $25(16.6)$ \\
\hline $40-49$ years & $60(39.7)$ \\
\hline$\geq 50$ years & $45(29.8)$ \\
\hline \multicolumn{2}{|l|}{ Men } \\
\hline $15-29$ years & $18(9.9)$ \\
\hline 30-39 years & $24(13.3)$ \\
\hline $40-49$ years & $68(37.6)$ \\
\hline$\geq 50$ years & $71(39.2)$ \\
\hline \multicolumn{2}{|l|}{ Highest level of education, no. (\%) } \\
\hline Some high school & $50(15.1)$ \\
\hline Completed high school & $87(26.2)$ \\
\hline Some post-secondary & $74(22.3)$ \\
\hline $\begin{array}{l}\text { Post-secondary/at least some graduate } \\
\text { education }\end{array}$ & $121(37.0)$ \\
\hline \multicolumn{2}{|c|}{ Number of hours working per week at time of injury, no. (\%) } \\
\hline$\leq 37.5$ & $111(33.4)$ \\
\hline$>37.5-40$ & $137(41.3)$ \\
\hline$>40$ & $84(25.3)$ \\
\hline \multicolumn{2}{|l|}{ Primary pain site, no. (\%) } \\
\hline Back & $215(64.8)$ \\
\hline Upper extremities & $117(35.2)$ \\
\hline \multicolumn{2}{|l|}{ Functional disability scale, mean (SD), median } \\
\hline Roland Morris (for back injuries) & 60.9 (27.2), 70.8 \\
\hline Quick DASH (for upper extremity injuries) & $53.5(21.1), 52.3$ \\
\hline Current pain intensity, mean (SD), median & $4.6(2.7), 4.5$ \\
\hline CES-D, mean (SD), median & $14.6(11.6), 11.0$ \\
\hline \multicolumn{2}{|l|}{ Working status, no. $(\%)$} \\
\hline Working at 1 month post-injury & $180(54.2)$ \\
\hline Not working at 1 month post-injury & $152(45.8)$ \\
\hline \multicolumn{2}{|l|}{ RTW trajectory, no. (\%) } \\
\hline Sustained 1st RTW & $162(49.1)$ \\
\hline RTW with at least 1 recurrence & $48(14.6)$ \\
\hline No RTW & $120(36.4)$ \\
\hline $\begin{array}{l}\text { Self-reported work absence duration } \\
\text { (standardized to a } 30 \text { day period), mean (SD), } \\
\text { median }\end{array}$ & $14.1(6.5), 14.0)$ \\
\hline
\end{tabular}

$S D$ standard deviation, no. number, $C E S-D$ Center for Epidemiologic Studies Depression Scale, $R T W$ return-to-work

* Data are based on self-reported interview data collected at baseline (approximately 1 month post-injury) 
Table 2 Cumulative incidence and prevalence of high levels of depressive symptoms at 12 months post-injury by sex, baseline depressive level, RTW trajectory, and RTW status

\begin{tabular}{|c|c|c|c|c|c|}
\hline \multirow[t]{2}{*}{ Sample } & \multicolumn{2}{|c|}{$\begin{array}{l}\text { Cumulative incidence of high levels of } \\
\text { depressive symptoms at } 12 \text { months }\end{array}$} & \multicolumn{2}{|c|}{$\begin{array}{l}\text { Prevalence of high levels of } \\
\text { depressive symptoms at } 12 \text { months }\end{array}$} & \multirow[t]{2}{*}{$\begin{array}{l}\text { Mean CES-D score (SD), } \\
\text { median at } 12 \text { months }\end{array}$} \\
\hline & $\mathrm{n} / \mathrm{N}$ & $\%(95 \% \mathrm{CI})$ & $\mathrm{n} / \mathrm{N}$ & $\%(95 \% \mathrm{CI})$ & \\
\hline Total sample $(\mathrm{n}=332)$ & $167 / 332$ & $50.3(44.9-55.7)$ & $82 / 332$ & $24.7(20.0-29.3)$ & $9.7(12.1), 4.0$ \\
\hline \multicolumn{6}{|l|}{ By sex } \\
\hline Men $(\mathrm{n}=181)$ & $80 / 181$ & $44.2(37.0-51.4)$ & $38 / 181$ & $21.0(15.1-26.9)$ & $8.2(10.9), 4.0$ \\
\hline Women $(\mathrm{n}=151)$ & $87 / 151$ & $57.6(49.7-65.5)$ & $44 / 151$ & $29.1(21.9-36.4)$ & $11.4(13.2), 6.0$ \\
\hline \multicolumn{6}{|c|}{ By depressive symptom level at baseline } \\
\hline Low levels $(\mathrm{n}=199)$ & & & $18 / 199$ & $9.1(5.1-13.0)$ & $4.9(7.1), 2.0$ \\
\hline High levels $(n=133)$ & & & $64 / 133$ & $48.1(39.6-56.6)$ & $16.7(14.3), 14.0$ \\
\hline \multicolumn{6}{|l|}{ By RTW trajectory at 12 months } \\
\hline RTW-S $(\mathrm{n}=136)$ & $48 / 136$ & $35.3(27.3-43.3)$ & $14 / 136$ & $10.3(5.2-15.4)$ & $5.4(7.5), 3.0$ \\
\hline RTW-R/No RTW (n = 196) & $119 / 196$ & $60.7(53.9-67.6)$ & $68 / 196$ & $34.7(28.0-41.4)$ & $12.6(13.7), 7.0$ \\
\hline \multicolumn{6}{|l|}{ By work status at 12 months } \\
\hline Currently working $(\mathrm{n}=257)$ & $113 / 257$ & $44.0(37.9-50.0)$ & $46 / 257$ & $17.9(13.2-22.6)$ & $7.4(9.9), 3.0$ \\
\hline Not working $(\mathrm{n}=75)$ & $54 / 75$ & $72.0(61.8-82.2)$ & $36 / 75$ & 48.0 (36.7-59.3) & 17.5 (15.3), 13.0 \\
\hline
\end{tabular}

\section{Course of Depressive Symptoms in the Overall Sample (Table 3)}

Most workers (64.2\%, $95 \%$ CI 59.0-69.3\%) experienced no change in their depressive symptom levels through the 12-month follow-up: $49.7 \%$ (95\% CI 44.3-55.1\%) did not experience high levels at any point over the 12-month follow-up period (low/low/low), while $14.5 \%$ of workers (95\% CI 10.7-18.2\%) had persistent high levels at all time points (high/high/high). An improvement in symptoms was seen by $25.6 \%$ of all workers $(95 \%$ CI 20.9-30.3\%). In particular, $15.4 \% \quad(95 \%$ CI 11.5-19.2\%) experienced a resolution of baseline high levels by 6 months and maintained those low levels through 12 months (high/low/low). Approximately $10.2 \%$ of workers (95\% CI 7.0-13.5\%) deteriorated over the 12-month follow-up period. The incidence of high levels at 12 months (low/low/high) was $3.6 \% \quad(95 \%$ CI $1.6-5.6 \%)$.

\section{Frequency of RTW Trajectory and Work Status Stratified by Symptom Course Group (Table 3)}

Half of all workers with a stable low course of symptoms (low/low/low; $53.3 \%, 95 \%$ CI $45.7-61.0 \%$ ) or with resolution of symptoms by 6 months (high/low/low; $47.1 \%$, $95 \%$ CI 33.4-60.8\%) had experienced a sustained first RTW trajectory by 12 months (Table 3 ). On the other hand, among workers with persistently high levels of depressive symptoms (high/high/high) over 12 months, only $10.4 \%$ (95 \% CI 1.8-9.1\%) had a RTW-S trajectory. In general, a lower proportion of workers whose course of symptoms included high levels at either 6 or 12 months had a successful RTW trajectory.

In terms of working status, the majority of workers whose course of symptoms included low levels at 12 months were working at 12 months (e.g., $87.3 \%$ of workers with stable low levels, $95 \%$ CI 82.2-92.4\%). Among workers whose course of symptoms included high levels at 12 months, there was generally no difference in the proportion of workers working versus not working at 12 months - the proportion working varied between 50 and $66.7 \%$. However, the latter findings need to be considered with caution due to small cell sizes, and large confidence intervals.

Overall, among workers with an improvement in symptoms, just under half had a RTW-S trajectory (40.0\%, $95 \%$ CI $29.6-50.4 \%)$ and almost $80 \%$ (78.8\%, $95 \%$ CI $70.1-87.5 \%$ ) were currently working at 12 months. In contrast, only $26.5 \% \quad(95 \%$ CI $11.6-41.3 \%)$ of workers who deteriorated experienced a sustainable first RTW and $58.8 \%$ (95\% CI 42.3-75.4\%) were working at 12 months.

\section{Course of Depressive Symptoms as a Function of Baseline Symptoms (Table 4)}

When examining the course of symptoms according to baseline levels (Table 4), it can be seen that the majority of workers $(82.9 \%, 95 \%$ CI 77.7-88.1\%) with low levels of depressive symptoms at baseline maintained low levels through 12 months. The incidence of high symptom levels at 12 months among those free of high levels at baseline was $6.0 \%$ (95\% CI 2.7-9.3\%). For workers with high 


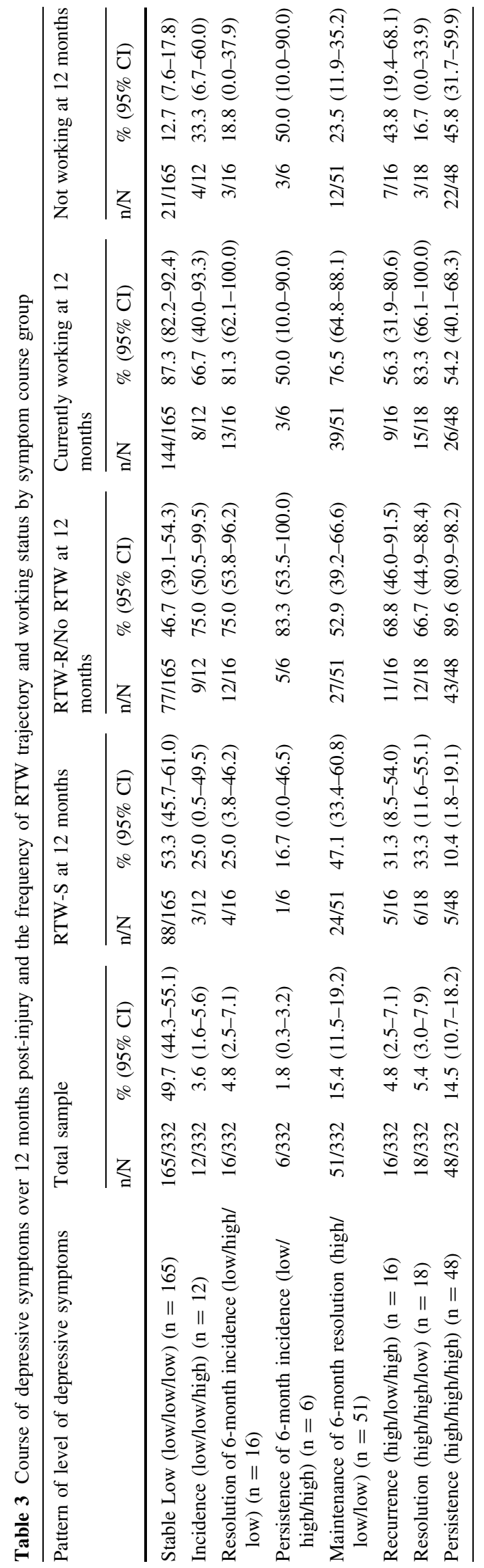

levels at baseline, just over half exhibited resolution, at either 6 months with maintenance through 12 months (38.4\%, $95 \%$ CI $30.1-46.6 \%$ ), or at 12 months post-injury $(13.5 \%, 95 \%$ CI 7.7-19.4\%). For workers with high symptom levels at baseline, persistent high levels at all interviews were demonstrated by $36.1 \% \quad(95 \%$ CI 27.9-44.3\%).

\section{Probability of Exhibiting a High or Low Symptom Level at 6 and 12 Months Conditional on the Symptom Level at the Time Point Immediately Preceding (Fig. 1)}

The conditional probabilities associated with the depressive symptom trajectories are presented in Fig. 1. Of note, $72.7 \%$ of workers with incident high depressive symptom levels at 6-month follow-up returned to low levels by 12 months ('Resolution of 6-Month Incidence'). Workers with high levels at baseline who had experienced resolution by 6 months generally maintained low levels at 12 months (76.1\%, 'Maintenance of 6-Month Resolution'). Likewise, workers with high levels through 6 months persisted with high levels at 12 months (72.7 \%, 'Persistence'). Overall, $81.3 \%$ of all workers at 12 months (270/332) continued to have the same levels at 12 months as experienced at 6 months.

Increasing the CES-D cutoff to 19 led to similar results (not shown). Men and women demonstrated similar symptom trajectories over the 12-month period (also not shown).

\section{Prevalence of a Depression Diagnosis and Mental Health Treatment at 6 and 12 Months for the Overall Sample and Stratified by Symptom Course Groups (Table 5)}

With respect to self-reported receipt of depression diagnosis and treatment, of the 12-month sample, $8.1 \%$ (95\% CI 5.2-11.1\%) reported receiving a depression diagnosis since their injury and $13.9 \%$ (95\% CI 10.1-17.6\%) reported current mental health treatment at 6 and/or 12 months post-injury (Table 5). When stratified by course of depressive symptoms, prevalence estimates of diagnosis and treatment at 12 months were generally highest for those with recent incident high levels ('Incidence') and with high levels at baseline, particularly those exhibiting 'Recurrence', 'Resolution', and 'Persistence' patterns. Among workers with persistent high symptoms (high/high/ high), $18.8 \%$ (95\% CI 7.7-29.8\%) reported receiving a diagnosis and $29.2 \%$ (95\% CI 16.3-42.0\%) reported receiving treatment at 12 months. These findings, however, need to be considered with caution, as the cell sizes were 
Table 4 Course of depressive symptoms over 12 months postinjury according to baseline symptom level

\begin{tabular}{lcc}
\hline Pattern of level of depressive symptoms & \multicolumn{2}{l}{ Total sample $(\mathrm{n}=332)$} \\
\cline { 3 - 3 } & $\mathrm{n} / \mathrm{N}$ & $\%(95 \% \mathrm{CI})$ \\
\hline Low levels at baseline $(\mathrm{n}=199)$ & & \\
$\quad$ Stable Low (low/low/low) & $165 / 199$ & $82.9(77.7-88.1)$ \\
Incidence (low/low/high) & $12 / 199$ & $6.0(2.7-9.3)$ \\
Resolution of 6-month incidence (low/high/low) & $16 / 199$ & $8.0(4.3-11.8)$ \\
Persistence of 6-month incidence (low/high/high) & $6 / 199$ & $3.0(0.6-5.4)$ \\
High levels at baseline (n = 133) & & \\
Maintenance of 6-month resolution (high/low/low) & $51 / 133$ & $38.4(30.1-46.6)$ \\
Recurrence (high/low/high) & $16 / 133$ & $12.0(6.5-17.6)$ \\
Resolution (high/high/low) & $18 / 133$ & $13.5(7.7-19.4)$ \\
Persistence (high/high/high) & $48 / 133$ & $36.1(27.9-44.3)$ \\
\hline
\end{tabular}

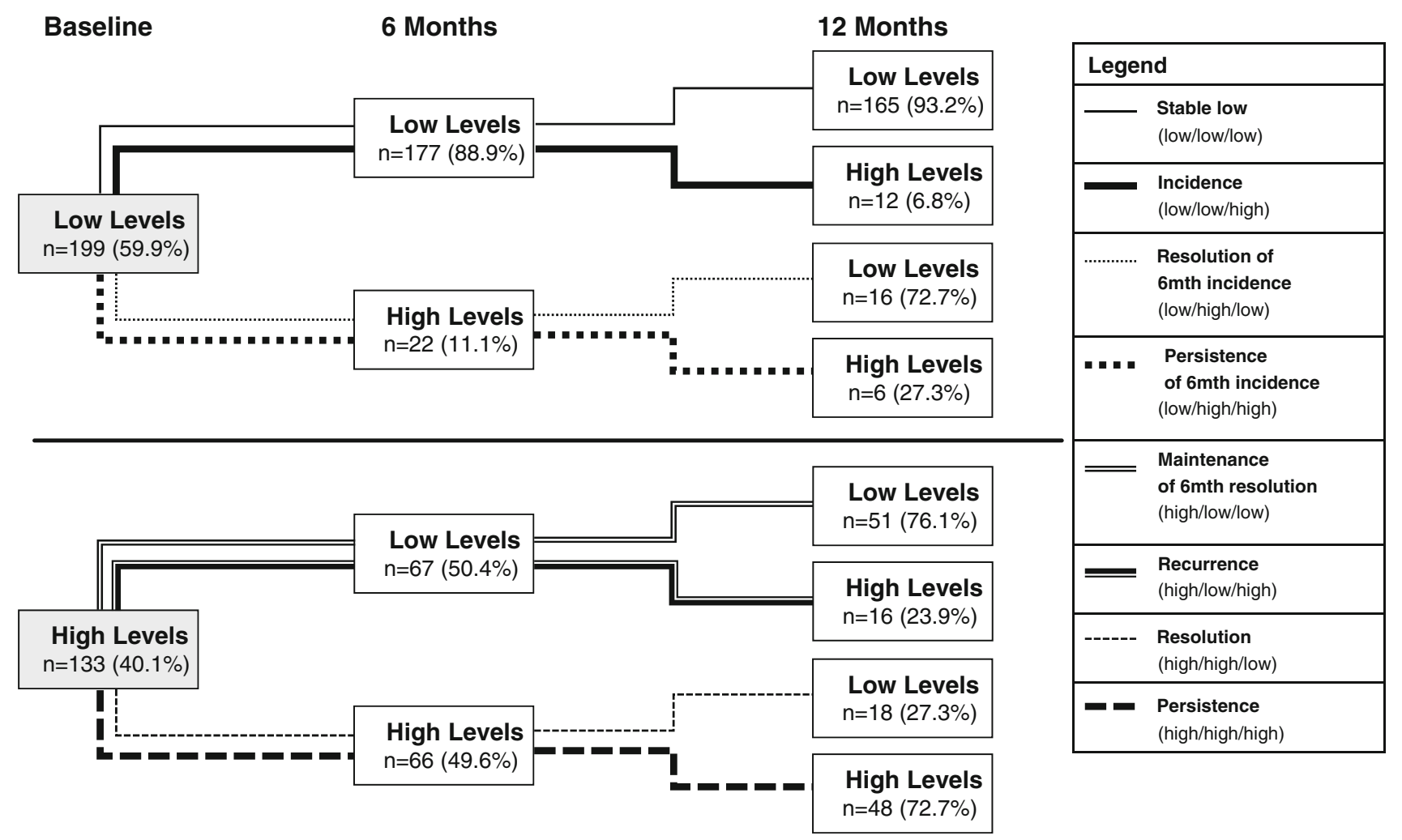

Fig. 1 Course of depressive symptoms over 12 months post-injury $(\mathrm{n}=332)$

small, and confidence intervals sometimes large. Mean CES-D scores at 12 months for those receiving a depression diagnosis by 12 months compared to those not receiving a diagnosis were 23.4 (SD 18.1, median 23.0) and 8.7 (SD 10.8, median 4.0), respectively. The mean CES-D score for those receiving treatment at 12 months was 20.3 (16.6, median 24.0). This is in contrast to the mean scores in those not receiving treatment at 12 months (mean 8.2, SD 10.6, median 4.0).

\section{Discussion}

The findings of this study suggest that, during the first 12 months following a work-related MSK injury, depressive symptoms are common, even in workers who report being depression-free 1 year prior to the work injury. Approximately 1 in 2 workers experience high depressive symptom levels at some point in the year following injury. However, the mental health of most workers appears to 
Table 5 Depression diagnosis and mental health treatment over a period of 12 months post-injury

\begin{tabular}{|c|c|c|c|c|c|c|}
\hline \multirow[t]{2}{*}{ Sample } & \multicolumn{2}{|c|}{$\begin{array}{l}\text { Received a depression } \\
\text { diagnosis between injury } \\
\text { date and } 12 \text { months } \\
\text { post-injury }\end{array}$} & \multicolumn{2}{|c|}{$\begin{array}{l}\text { Using anti-depressants } \\
\text { and/or consulting with a } \\
\text { healthcare provider about } \\
\text { mental health at } 6 \text { months }\end{array}$} & \multicolumn{2}{|c|}{$\begin{array}{l}\text { Using anti-depressants } \\
\text { and/or consulting with a } \\
\text { healthcare provider about } \\
\text { mental health at } \\
12 \text { months }\end{array}$} \\
\hline & $\mathrm{n} / \mathrm{N}$ & $\%(95 \% \mathrm{CI})$ & $\mathrm{n} / \mathrm{N}$ & $\%(95 \% \mathrm{CI})$ & $\mathrm{n} / \mathrm{N}$ & $\%(95 \% \mathrm{CI})$ \\
\hline Total sample $(\mathrm{n}=332)$ & $27 / 332$ & $8.1(5.2-11.1)$ & $27 / 332$ & $8.1(5.2-11.1)$ & $39 / 332$ & $11.8(8.3-15.2)$ \\
\hline \multicolumn{7}{|l|}{ By sex } \\
\hline $\operatorname{Men}(\mathrm{n}=181)$ & $12 / 181$ & $6.6(3.0-10.3)$ & $10 / 181$ & $5.5(2.2-8.9)$ & $12 / 181$ & $6.6(3.0-10.3)$ \\
\hline Women $(\mathrm{n}=151)$ & $15 / 151$ & $9.9(5.2-14.7)$ & $17 / 151$ & $11.3(6.2-16.3)$ & $27 / 151$ & $17.9(11.8-24.0)$ \\
\hline \multicolumn{7}{|c|}{ By course of depressive symptoms between baseline and 12 months } \\
\hline Stable Low (low/low/low) $(\mathrm{n}=165)$ & $0 / 165$ & $0(0.0-0.0)$ & $6 / 165$ & $3.6(0.8-6.5)$ & $9 / 165$ & $5.5(2.0-8.9)$ \\
\hline Incidence (low/low/high) $(\mathrm{n}=12)$ & $3 / 12$ & $25.0(0.0-49.5)$ & $1 / 12$ & $8.3(0.0-24.0)$ & $4 / 12$ & $33.3(6.7-60.0)$ \\
\hline Resolution of 6-month incidence (low/high/low) $(\mathrm{n}=16)$ & $2 / 16$ & $12.5(0.0-28.7)$ & $1 / 16$ & $6.3(0.0-18.1)$ & $2 / 16$ & $12.5(0.0-28.7)$ \\
\hline Persistence of 6-month incidence (low/high/high) $(\mathrm{n}=6)$ & $0 / 6$ & $0(0.0-0.0)$ & $0 / 6$ & $0(0.0-0.0)$ & $0 / 6$ & $0(0.0-0.0)$ \\
\hline $\begin{array}{l}\text { Maintenance of 6-month resolution (high/low/low) } \\
(\mathrm{n}=51)\end{array}$ & $7 / 51$ & $13.7(4.3-23.2)$ & $1 / 51$ & $2.0(0.0-5.8)$ & $3 / 51$ & $5.9(0.0-12.3)$ \\
\hline Recurrence (high/low/high) $(\mathrm{n}=16)$ & $3 / 16$ & $18.8(0.0-37.9)$ & $3 / 16$ & $18.8(0.0-37.9)$ & $3 / 16$ & $18.8(0.0-37.9)$ \\
\hline Resolution (high/high/low) $(\mathrm{n}=18)$ & $3 / 18$ & $16.7(0.0-33.9)$ & $2 / 18$ & $11.1(0.0-25.6)$ & $4 / 18$ & $22.2(3.0-41.4)$ \\
\hline Persistence (high/high/high) $(\mathrm{n}=48)$ & $9 / 48$ & $18.8(7.7-29.8)$ & $13 / 48$ & $27.1(14.5-39.7)$ & $14 / 48$ & $29.2(16.3-42.0)$ \\
\hline
\end{tabular}

improve over time during the first 12 months following injury. Our findings demonstrate that, for workers with low baseline levels of depressive symptoms, levels of depressive symptoms 1 month post-injury are a fair indicator of 6- and 12-month levels; for workers with high baseline levels of depressive symptoms, depressive symptoms tend to stabilize at 6 months post-injury. Finally, problematic RTW outcomes appear to be more common among workers with poorer depressive symptom trajectories.

As we previously demonstrated over 6 months followup [3], high depressive symptom levels appear to peak shortly after injury, with $42.9 \%$ of workers experiencing high levels at 1 month post-injury and $26.5 \%$ experiencing high levels at 6 months. By 12 months, little change had occurred in the prevalence of high levels $(24.7 \%)$ and very few $(3.6 \%)$ developed high levels at 12 months after having low levels at 1 and 6 months. Furthermore, only $10 \%$ of workers experienced a deterioration in symptoms over 1 year, while $25.6 \%$ demonstrated an improvement. These findings support the notion that depressive symptoms may be a natural response to experiencing a workplace injury.

The first 6-month period post-injury appears particularly important. In our previous analysis [3], workers with high depressive symptom levels at 1 month post-injury were equally likely to experience symptom persistence or resolution by 6 months. Current analyses suggest that, for most workers with high levels shortly after injury, levels at 6 months stabilize and are generally indicative of 12-month symptom levels, although both resolution and recurrence of depressive symptoms do occur after 6 months for 13.5 and $12 \%$ of these workers, respectively. Overall, almost half of all workers (48.1\%) with high levels at 1 month post-injury also have high levels at 12 months. Conversely, our findings suggest that depressive symptoms apparent early on post-injury are fair predictors of later depressive status for workers with low levels at baseline: of the $60 \%$ of injured workers experiencing no or few depressive symptoms at baseline, $17 \%$ of them go on to experience depressive symptoms later on during the first year post-injury (at either 6 or 12 months) and $9.1 \%$ have high levels at 12 months post-injury. As well, those who develop high depressive symptom levels appear more likely to do so within 6 months post-injury.

Despite some variability in the trajectory of symptoms, these findings demonstrate a relative stability of depressive symptoms after 6 months post-injury. This suggests that the first 6 months, corresponding to the acute and sub-acute phases of work disability [26, 27], may represent a window of opportunity for both screening and early detection of those at risk for depressive symptoms, as well as possible early intervention. The practice of screening workers early on for the presence of depressive symptoms is already beginning to be considered [28] and implemented in workers' compensation boards [29]. Providing early intervention to those with high levels of depressive symptoms could shift their depressive symptoms towards a lower level at 6 month post-injury, a time point where the 
depressive symptoms appear to stabilize, and which corresponds to the chronic phase of work disability [26, 27].

By 12 months post-injury, $14.5 \%$ of workers had persistent high levels at all time points and a quarter $(24.7 \%)$ were experiencing high levels of depressive symptoms at 12 months. Prevalence estimates of high depressive symptom levels based on the CES-D in the general working population have ranged from 14 to $23 \%[30,31]$ and 11 to $25 \%$ in the general community [32-35]. Given the wide ranges reported, it is difficult to ascertain whether depressive symptoms are, in fact, more prevalent in injured workers at 12 months. Perhaps a more important consideration, however, is the potential impact of persistently high and deteriorating symptom levels over time on the injured worker.

Consistent with our previous findings [3], we found that depressive symptoms were more common among workers having difficulty returning to work and that workers with a problematic depressive symptom course were less likely to have a favourable RTW trajectory or to be at work by 12 months. In particular, only $10.4 \%$ of workers with persistently high levels at all 3 interviews had a sustained RTW trajectory and, among the $10 \%$ with deteriorating symptom levels, only a quarter $(26.5 \%)$ experienced a sustained RTW by 12 months. This group, while small, may represent a high-risk group for prolonged work disability. Previous research has shown depression to be a risk factor for MSK-related work disability [4, 6-9] and workers with MSK-related work disability exceeding a year are responsible for a large percentage of workers' compensation costs and total disability days [36-38]. These findings further highlight the importance of early screening for depressive symptoms and possible intervention.

However, it is important to emphasize that the direction of causality could not be determined from these data. That is, did the depressive symptoms lead to RTW difficulties or did RTW difficulties contribute to poor mental health? The likely answer is that both conditions are involved in a complex mutual interaction. Previous studies have highlighted the bidirectional relationship of (work-related) pain and depression [39, 40]. Potential mediating processes could involve symptoms of depression, such as low selfefficacy, loss of interest in work, low energy, and eliciting negative responses from employers and other RTW partners, leading to increased stigmatization. Future studies should focus on better understanding this complex interaction between depression, injury-related pain, and relationships with RTW partners.

As expected, the cumulative incidence of high depressive symptom levels at 12 months was higher among women $(57.6 \%)$ compared to men $(44.2 \%)$. The prevalence of high symptom levels demonstrated a similar pattern, though differences were not significant. Surprisingly, there was little difference in the course of depressive symptoms between men and women (details available upon request). These findings suggest that while depressive symptoms may be more common among women, the actual temporal trajectory of symptoms after a workplace injury may not depend on sex. These findings should be further explored in a multivariate analysis that adequately controls for confounding by known depression risk factors, such as social support and psychological constructs [41-43].

In most groups, anywhere from 2 to $33 \%$ of workers reported receiving treatment at either 6 or 12 months. In general, our findings demonstrate that the prevalence of depression diagnosis and treatment is highest among those with higher depressive symptom levels at 12 months and a poorer course of symptoms. However, among workers with persistent high symptoms, only $18.8 \%$ reported receiving a diagnosis and $29.2 \%$ reported receiving treatment at 12 months. Depression has been previously shown to be under diagnosed [44, 45] and undertreated [46, 47]. In our study, it is difficult to draw any conclusions regarding the extent of appropriate diagnosis and treatment in injured workers for a number of reasons. Namely, cell sizes were extremely small in a number of the course groups, reducing the precision of our estimates. Furthermore, the CES-D is a self-report measure not intended to yield a clinical diagnosis and, as such, those with high depressive symptom levels did not necessarily have clinical depression necessitating treatment. Further research is needed to better understand which injured workers would benefit from depression treatment after an injury.

We restricted our sample to injured workers who reported that they had not received a diagnosis of depression in the year prior to injury. This restriction has implications for the causal nature of the depressive symptoms seen after injury. Causality analyses are an important element of workers' compensation processes as they are critical to determining the compensability of a condition, i.e., depression within the context of a workrelated injury. Our study suggests that a work injury, in a population of workers who self-report no depression diagnosis in the year prior to the injury, may contribute to the development of high levels of depressive symptoms. Of course, this consideration needs to be tempered by the fact that the absence of a diagnosis of depression was based on retrospective self-report only and that no measure of depressive symptoms was given prior to injury. Nevertheless, our findings reinforce the conclusions of at least one previous study which demonstrated that major depressive disorder was more likely to develop after the onset of a work-related back injury [48]. The issue of the potential causal role of a work injury in the development of depressive symptoms is an area that is understudied, and our study makes a modest contribution to this area of 
research. Future research on identification of workers most vulnerable to the development of depressive symptoms post-injury would be fruitful.

No study, to our knowledge, has examined the course of depressive symptoms in injured workers. Findings of a similar study [33] documenting course of symptoms following whiplash among automobile insurance claimants are consistent with our results, with depressive symptoms peaking following injury, and with resolution more likely to occur within the first few months, although persistence and recurrence of symptoms are common.

Findings of our study need to be interpreted in light of the findings of attrition bias analyses comparing participants at 12 months to those lost to 12-month follow-up (details available upon request). These analyses suggested that (1) participants lost to follow-up had more depressive symptoms, pain, and poorer functional status at baseline than participants; (2) participants lost to follow-up were more likely to have received a depression diagnosis and treatment by 6 months; and (3) among workers with high baseline depressive symptom levels, those lost to follow-up were more likely than participants to demonstrate resolution of high symptom levels. Therefore, the proportion of workers experiencing symptoms at baseline and those experiencing a resolving course of symptoms may have been underestimated in our study.

Other limitations of our study include the self-reported nature of the data and small sample size. In particular, the cell sizes for some of the course groups in Tables 3 and 5 were extremely small, compromising the precision of our estimates. As such, these findings should be considered with caution. Use of a cutoff of 16 on the CES-D may also be considered a limitation, as there is no consensus in the literature on the most valid cutoff for depression screening. A cutoff of 16 is most widely used, but has been criticized for being too low, leading to a high number of false positives and low PPV values [17, 18, 20, 22]. Still, while workers in this study who scored above 16 may not have had clinical depression, we have shown that even subthreshold depressive symptoms are related to poorer RTW outcomes, a finding that is consistent with other research demonstrating a relationship between subthreshold depression and functional impairment [49-51]. Previous literature suggests that using a cutoff score of 19 may be more appropriate for chronic pain patients [21]. Importantly, in our study, increasing the cutoff to 19 did not lead to significant differences in our findings (details available upon request). Given the data collection schedule, we also could not determine the precise month in which depressive symptoms developed, nor when RTW occurred. For instance, a worker with incident high levels at 6 months may have developed high levels at 3 months. This precluded our ability to examine the direction of the relationship between course of depressive symptoms and RTW. While we excluded workers reporting a depression diagnosis in the year before injury (to minimize the likelihood that workers already had depression at the time of injury), we did not have data on lifetime depression occurrence. As such, the extent to which workers may have been more vulnerable to a recurrence of symptoms after injury due to a prior history is unclear. Finally, our study was conducted in the mid 2000s. Since then, there have been a number of changes that may affect the experience of injured workers. These include changes in the workplace (e.g., technological advances), changes in workers' compensation systems (e.g., a trend toward compensability of mental health conditions), and societal changes (e.g., increased awareness of and sensitivity to mental health conditions and their impact). Therefore, the generalizability of our findings to today's injured worker may be somewhat limited.

Depressive symptoms are common in the first year after a work injury, and a poor course of symptoms is associated with problematic RTW outcomes over 12 months post-injury. However, symptoms appear to improve over time. For injured workers with low levels of depressive symptoms early on, levels of depressive symptoms 1 month post-injury are fair predictors of 6- and 12-month levels; for workers with high levels of depressive symptoms early on, depressive symptoms tend to stabilize at 6 months postinjury and are a good indicator of 12-month levels. Importantly, these findings support the notion that the first 6 months post-injury are particularly important in establishing future depressive symptom levels and may be a window of opportunity for early screening. Future research should establish if early screening and intervention for depressive symptoms can lead to prevention of depressive symptoms, improved management, and better RTW outcomes. Likewise, researchers should focus on evaluating the effectiveness of work-focused interventions in this population, both in terms of timing and nature of intervention. Future research should also focus on identifying the worker, workplace, and system factors associated with poorer depressive symptom trajectories, and the direction of the relationship between poor depressive symptom course and RTW outcomes.

Acknowledgments We would like to thank Marjan Vidmar and Hyunmi Lee for preparing and managing the data for this study. Nancy Carnide was supported by a Vanier Canada Graduate Scholarship from the Canadian Institutes of Health Research during the conduct of this research.

\section{Compliance with Ethical Standards}

Contributors Renée-Louise Franche and Sheilah Hogg-Johnson conceptualized and designed the study. Renée-Louise Franche supervised the study. Colette Severin was responsible for 
coordinating the project. Nancy Carnide and Renée-Louise Franche performed the statistical analyses with substantive feedback from Sheilah Hogg-Johnson, Pierre Côté, F. Curtis Breslin, Colette Severin, Ute Bültmann, and Niklas Krause. Nancy Carnide and Renée-Louise Franche wrote the paper. All authors critically reviewed the manuscript and approved the final version.

Funding This study was funded by a research grant provided by the Workplace Safety and Insurance Board of Ontario (WSIB) and by the Social Science and Humanities Research Council - Research Action Alliance on Consequences of Work Injury (RAACWI). WSIB was involved in providing feedback on the questionnaire used in this study and in the recruitment of participants, only. WSIB was not involved in the analysis, interpretation of data, writing, and decision to submit this paper for publication. RAACWI did not have direct input in this project. The Institute for Work \& Health operates with the support of the Province of Ontario. The views expressed in this document are those of the authors and do not necessarily reflect those of the Province of Ontario.

Ethical Standard This study was approved by the University of Toronto's Ethics Review Board. All procedures followed were in accordance with the ethical standards of the responsible committee on human experimentation (institutional and national) and with the Helsinki Declaration of 1975, as revised in 2000 (5). Informed consent was obtained from all patients for being included in the study.

Conflict of interest Nancy Carnide, Pierre Côté, Colette Severin, Ute Bültmann, and Niklas Krause declare that they have no conflict of interest. Salaries for Renée-Louise Franche, F. Curtis Breslin, and Sheilah Hogg-Johnson at the Institute for Work \& Health came from a core funding grant from the Workplace Safety \& Insurance Board during the conduct of this research

\section{References}

1. Association of Workers' Compensation Boards of Canada. National Work Injury/Disease Statistics Program (NWISP): 2013 Injury Statistics. Mississauga, ON. http://awcbc.org/?page_id= 14\#injuries. Last accessed 13 March 2015.

2. Dersh J, Gatchel RJ, Mayer T, Polatin P, Temple OR. Prevalence of psychiatric disorders in patients with chronic disabling occupational spinal disorders. Spine. 2006;31(10):1156-62.

3. Franche RL, Carnide N, Hogg-Johnson S, Côté P, Breslin FC, Bültmann U, et al. Course, diagnosis, and treatment of depressive symptomatology in workers following a workplace injury: a prospective cohort study. Can J Psychiatry. 2009;54(8):534-46.

4. Keogh JP, Nuwayhid I, Gordon JL, Gucer PW. The impact of occupational injury on injured worker and family: outcomes of upper extremity cumulative trauma disorders in Maryland workers. Am J Ind Med. 2000;38(5):498-506.

5. Kim J. Depression as a psychosocial consequence of occupational injury in the US working population: findings from the medical expenditure panel survey. BMC Public Health. 2013;5(13):303-13.

6. Corbière M, Sullivan MJ, Stanish WD, Adams H. Pain and depression in injured workers and their return to work: a longitudinal study. Can J Behav Sci/Revue canadienne des sciences du Comportement. 2007;39(1):23-31.

7. Dozois DJA, Dobson KS, Wong M, Hughes D, Long A. Factors associated with rehabilitation outcome in patients with low back pain (LBP): prediction of employment outcome at 9-month follow-up. Rehabil Psychol. 1995;40(4):243-59.

8. Garcy P, Mayer T, Gatchel RJ. Recurrent or new injury outcomes after return to work in chronic disabling spinal disorders. Tertiary prevention efficacy of functional restoration treatment. Spine. 1996;21(8):952-9.

9. Lötters F, Franche RL, Hogg-Johnson S, Burdorf A, Pole JD. The prognostic value of depressive symptoms, fear-avoidance, and self-efficacy for duration of lost-time benefits in workers with musculoskeletal disorders. Occup Environ Med. 2006;63(12): 794-801.

10. Bültmann U, Franche RL, Hogg-Johnson S, Côté P, Lee H, Severin C, et al. Health status, work limitations, and return-towork trajectories in injured workers with musculoskeletal disorders. Qual Life Res. 2007;16(7):1167-78.

11. Franche RL, Severin CN, Hogg-Johnson S, Côté P, Vidmar M, Lee $\mathrm{H}$. The impact of early workplace-based return-to-work strategies on work absence duration: a 6-month longitudinal study following an occupational musculoskeletal injury. J Occup Environ Med. 2007;49(9):960-74.

12. Franche RL, Severin CN, Hogg-Johnson S, Lee H, Côté P, Krause N. A multivariate analysis of factors associated with early offer and acceptance of a work accommodation following an occupational musculoskeletal injury. J Occup Environ Med. 2009;51(8):969-83.

13. Cassidy JD, Côté P, Carroll LJ, Kristman V. Incidence and course of low back pain episodes in the general population. Spine. 2005;30(24):2817-23.

14. Sinclair SJ, Hogg-Johnson SH, Mondloch MV, Shields SA. The effectiveness of an early active intervention program for workers with soft-tissue injuries. The Early Claimant Cohort Study. Spine. 1997;22(24):2919-31.

15. Radloff LS. The CES-D scale: a self-report depression scale for research in the general population. Appl Psychol Meas. 1977;1(3):385-401.

16. Boyd JH, Weissman MM, Thompson WD, Myers JK. Screening for depression in a community sample. Understanding the discrepancies between depression symptom and diagnostic scales. Arch Gen Psychiatry. 1982;39(10):1195-200.

17. Geisser ME, Roth RS, Robinson ME. Assessing depression among persons with chronic pain using the Center for Epidemiological Studies-Depression Scale and the Beck Depression Inventory: a comparative analysis. Clin J Pain. 1997;13(2): $163-70$.

18. Klinkman MS, Coyne JC, Gallo S, Schwenk TL. Can case-finding instruments be used to improve physician detection of depression in primary care? Arch Fam Med. 1997;6(6):567-73.

19. Martens MP, Parker JC, Smarr KL, Hewett JE, Slaughter JR, Walker SE. Assessment of depression in rheumatoid arthritis: a modified version of the center for epidemiologic studies depression scale. Arthritis Rheum. 2003;49(4):549-55.

20. Schulberg HC, Saul M, McClelland M, Ganguli M, Christy W, Frank R. Assessing depression in primary medical and psychiatric practices. Arch Gen Psychiatry. 1985;42(12):1164-70.

21. Turk DC, Okifuji A. Detecting depression in chronic pain patients: adequacy of self-reports. Behav Res Ther. 1994;32(1):9-16.

22. Zich JM, Attkisson CC, Greenfield TK. Screening for depression in primary care clinics: the CES-D and the BDI. Int J Psychiatry Med. 1990;20(3):259-77.

23. Von Korff M, Jensen MP, Karoly P. Assessing global pain severity by self-report in clinical and health services research. Spine. 2000;25(24):3140-51.

24. Roland M, Morris R. A study of the natural history of back pain. Part I: development of a reliable and sensitive measure of disability in low-back pain. Spine. 1983;8(2):141-4.

25. Beaton DE, Wright JG, Katz JN. Development of the QuickDASH: comparison of three item-reduction approaches. J Bone Joint Surg Am. 2005;87(5):1038-46.

26. Frank J, Sinclair S, Hogg-Johnson S, Shannon H, Bombardier C, Beaton D, et al. Preventing disability from work-related low-back 
pain. New evidence gives new hope-if we can just get all the players onside. CMAJ. 1998;158(12):1625-31.

27. Spitzer WO, LeBlanc FE, Dupuis M, Abenhaim L, Belanger AY, Bloch R, et al. Scientific approach to the assessment and management of activity-related spinal disorders. A monograph for clinicians. Report of the Quebec Task Force on Spinal Disorders. Spine. 1987;12(7 Suppl):S1-59.

28. Steenstra IA, Franche R-L, Busse JW, Tolusso D, Davilmar A, Lee $\mathrm{H}$, et al. Predicting time on benefits for injured workers with back pain, what additional information should be collected? International Work Disability and Integration Conference; October 2014; Toronto, ON Canada.

29. Franche R-L. Innovative practices to improve recovery and return-to-work of workers: psychosocial factors at the front end and tail end of the claim. Keynote address. Australasian Compensation Health Research Forum; November 19, 2014; Melbourne, Australia.

30. Iwata N, Okuyama Y, Kawakami Y, Saito K. Prevalence of depressive symptoms in a Japanese occupational setting: a preliminary study. Am J Public Health. 1989;79(11):1486-9.

31. Wada K, Satoh T, Tsunoda M, Aizawa Y. Associations of health behaviors on depressive symptoms among employed men in Japan. Ind Health. 2006;44(3):486-92.

32. Barnes GE, Currie RF, Segall A. Symptoms of depression in a Canadian urban sample. Can J Psychiatry. 1988;33(5):386-93.

33. Carroll LJ, Cassidy JD, Côté P. Frequency, timing, and course of depressive symptomatology after whiplash. Spine. 2006;31(16): E551-6.

34. Eaton WW, Kessler LG. Rates of symptoms of depression in a national sample. Am J Epidemiol. 1981;114(4):528-38.

35. Grucza RA, Przybeck TR, Spitznagel EL, Cloninger CR. Personality and depressive symptoms: a multi-dimensional analysis. J Affect Disord. 2003;74(2):123-30.

36. Hashemi L, Webster BS, Clancy EA. Trends in disability duration and cost of workers' compensation low back pain claims (1988-1996). J Occup Environ Med. 1998;40(12):1110-9.

37. Hashemi L, Webster BS, Clancy EA, Courtney TK. Length of disability and cost of work-related musculoskeletal disorders of the upper extremity. J Occup Environ Med. 1998;40(3):261-9.

38. Hashemi L, Webster BS, Clancy EA, Volinn E. Length of disability and cost of workers' compensation low back pain claims. J Occup Environ Med. 1997;39(10):937-45.
39. Currie SR, Wang J. Chronic back pain and major depression in the general Canadian population. Pain. 2004;107(1-2):54-60.

40. Fishbain DA, Cutler R, Rosomoff HL, Rosomoff RS. Chronic pain-associated depression: antecedent or consequence of chronic pain? A review. Clin J Pain. 1997;13(2):116-37.

41. Bagby RM, Psych C, Quilty LC, Ryder AC. Personality and depression. Can J Psychiatry. 2008;53(1):14-25.

42. Santini ZI, Koyanagi A, Tyrovolas S, Mason C, Haro JM. The association between social relationships and depression: a systematic review. J Affect Disord. 2015;175:53-65.

43. Mongrain M, Leather F. Immature dependence and self-criticism predict the recurrence of major depression. J Clin Psychol. 2006;62(6):705-13.

44. Coyne JC, Schwenk TL, Fechner-Bates S. Nondetection of depression by primary care physicians reconsidered. Gen Hosp Psychiatry. 1995;17(1):3-12.

45. Wells KB, Hays RD, Burnam MA, Rogers W, Greenfield S, Ware JE Jr. Detection of depressive disorder for patients receiving prepaid or fee-for-service care. Results from the Medical Outcomes Study. JAMA. 1989;262(23):3298-302.

46. Kessler RC, Zhao S, Katz SJ, Kouzis AC, Frank RG, Edlund M, et al. Past-year use of outpatient services for psychiatric problems in the National Comorbidity Survey. Am J Psychiatry. 1999;156(1):115-23.

47. Wang PS, Berglund P, Kessler RC. Recent care of common mental disorders in the United States : prevalence and conformance with evidence-based recommendations. J Gen Intern Med. 2000;15(5):284-92.

48. Dersh J, Mayer T, Theodore BR, Polatin P, Gatchel RJ. Do psychiatric disorders first appear preinjury or postinjury in chronic disabling occupational spinal disorders? Spine. 2007;32(9): 1045-51.

49. Cuijpers P, de Graaf R, van Dorsselaer S. Minor depression: risk profiles, functional disability, health care use and risk of developing major depression. J Affect Disord. 2004;79(1-3):71-9.

50. Karsten J, Penninx BW, Verboom CE, Nolen WA, Hartman CA Course and risk factors of functional impairment in subthreshold depression and anxiety. Depress Anxiety. 2013;30(4):386-94.

51. Williams JW Jr, Kerber CA, Mulrow CD, Medina A, Aguilar C. Depressive disorders in primary care: prevalence, functional disability, and identification. J Gen Intern Med. 1995;10(1):7-12. 